\title{
La inactualidad del comunismo: la herencia (Lenin) y la promesa (Gramsci) en la obra de Roque Dalton'
}

Resumen: Las dos figuras a partir de las cuales me acerco a la obra de Roque Dalton y a esa promesa de emancipación radical que fue el comunismo, serán la herencia y la promesa de felicidad que es todo futuro utópico. Ambas problemáticas serán leídas desde una perspectiva poética. Estos principios serán personalizados a través de dos grandes figuras: Vladimir Lenin y Antonio Gramsci. El gran tema del libro sobre Lenin que escribió Dalton es el problema de la herencia. El futuro lo vincularé a Gramsci debido a la importancia que ha adquirido su figura de la mano de pensadores como Ernesto Laclau y Chantal Mouffe en movimientos populares en Europa tanto como en América Latina. Los dos problemas, el de la herencia y el del futuro, están estrechamente vinculados entre sí. Ambos problemas, además, los interpretaré desde la noción que a los mismos les impone el lenguaje de Dalton, por lo que no usaré el pensamiento de Lenin y Gramsci para interpretar la obra de Dalton. Leeré la poesía de Dalton para interpelar a estas figuras y ver la validez que puedan tener para nuestra historia actual.

Abstract: In this essay, I read Roque Dalton's poetic work and attempt to understand the promise behind communism, one of the most radical emancipatory projects created by humans, through two concepts: inheritance and the promise of happiness that characterizes every utopian project for the future. I will approach both concepts through a poetic lens. I ascribe each of these concepts to two influential thinkers: Vladimir Lenin and Antonio Gramsci. Dalton, in his book about Lenin, attempts to understand how to inherit the communist legacy in Latin America. I will link the promise of the future to Gramsci given the great relevance of his work in contemporary thinkers such as Ernesto Laclau and Chantal Mouffe in contemporary leftist populist movements in Europe and Latin America. I will interpret the two problems, that of inheritance and the future, using Dalton's own language and thinking. I will use Dalton's poetry to understand the validity that concepts such as inheritance and the promise for the future may have for us now. 
Palabras clave: Dalton, Lenin, Gramsci, herencia, promesa, futuro, comunismo, pueblo, hegemonía
Key Words: Dalton, Lenin, Gramsci, inheritance, promise, future, communism, people, hegemony

"Quienes dicen que el arte no debe propagar doctrinas, suelen referirse a doctrinas contrarias a las suyas".

\section{Jorge Luis Borges, Otras Inquisiciones}

Un poeta puede trascender de muchas maneras. Suele suceder que olvidamos el proyecto intelectual que un poeta construyó: los pensamientos, las filiaciones, los gestos que configuraron su trayectoria intelectual, las ideas por las que combatió; y nos quedamos con un puñado de poemas que tratan de resumir un tono, una VOz, cierta forma de configurar el tiempo con palabras. Se han olvidado, por ejemplo, todos los tratados que Quevedo escribió sobre el estado o la naturaleza de Dios pero muchos de sus poemas configuran el canon de lo que hoy entendemos por gran poesía en español. Se ha tratado de olvidar, para poner otro ejemplo, o al menos minimizar, el claro apoyo que Borges le dio al principio a la dictadura en la Argentina: "Al fin vamos a tener un gobierno de caballeros", 2 fueron sus palabras. Y nos hemos quedado con el "Poema de los dones" o con sus textos recogidos en Ficciones y El aleph. Hay otros poetas que sufren un destino diferente. La consagración de Neruda como poeta continental tuvo que ver con el rol que él mismo se adjudicó de otorgarle voz a los desposeídos, a los que la historia nunca había dejado hablar. Cuando se impusieron otros modelos de representación y se empezó a desconfiar del intelectual como portavoz de las clases subalternas y se buscó modos de acceso de intervención en la esfera pública más allá de las formas de representación tradicionales, la figura de Neruda perdió prestigio, al menos como la figura del gran poeta latinoamericano, pero esto no impidió que muchos de sus poemas y poemarios: Residencia en la tierra o "Walking around", por solo citar dos ejemplos, sigan siendo considerados imprescindibles. El destino de los poetas, por tanto, su suerte en la posteridad, mantiene una relación aleatoria con el proyecto intelectual que informó en sus versos. Pero si esto es cierto respecto a la forma en que se transmiten los poemas y se distribuyen los roles en el canon en las diferentes tradiciones nacionales y/o lingüísticas, no se puede decir lo mismo de la forma en que la poesía sobrevive, se consagra, se convierte en baladí, (esto también puede ser una de las formas de la consagración), o se obsoleta a través de la historia. La poesía constituye un proyecto intelectual tan ambicioso y totalizador como puede 
ser un sistema de pensamiento filosófico, una teoría científica o un movimiento social que trata de reinventar las formas en que los seres viven e interactúan. Cada gran poeta inventa un mundo y este mundo se constituye por tonos, acentos, percepciones, afectos, ideas, dogmas, gestos, acciones, posturas, compromisos, rechazos, batallas, entre otros. La poesía de Roque Dalton vinculó su palabra de un modo raigal, profundo, ineludible al proyecto de emancipación más radical que han imaginado los humanos. Un proyecto que proponía, según uno de sus creadores, que los humanos dejaran de ser simples intérpretes de la historia para dedicarse a transformarla. Hacer, luego de tantos siglos, una historia a la medida de los mejores anhelos humanos. Hace ya casi un siglo, se inició una revolución que decía encarnar ese ideal, y luego del reparto geopolítico que supuso la caída del fascismo hubo todo un bloque de países que pretendieron convertir en leyes de la historia aquellos principios que hasta ese momento solamente habían sido ideales utópicos. Incluso, los aires de esos cambios llegaron a nuestro continente y hubo al menos un país en América que se declaró socialista y que aspiraba a ser comunista. Ese era el nombre del proyecto emancipatorio más audaz inventado por los hombres. Pero como sabemos, las cosas no fueron tan bien. Murieron millones de hombres, incluido nuestro propio poeta, que fueron sacrificados en nombre de aquellos ideales, y el mundo siguió siendo ancho y ajeno o, lo que es lo mismo, capitalista, globalizado, despiadado, intolerablemente injusto. Como dice Eduardo Galeano en El libro de los abrazos: "el socialismo es el camino más largo para llegar del capitalismo al capitalismo" (Galeano, 1993, p. 96). O como gritó uno de los más desgarrados y sinceros escritores que habían vivido esa experiencia en carne propia, Reinaldo Arenas: "Vengo del futuro y traigo malas noticias". ¿Pero el futuro solamente trae males noticias? ¿Se puede rescatar y heredar algo, y en eso nos va mucho de nuestra dignidad como seres humanos, de aquella experiencia que calificamos como el mejor sueño emancipador que crearon los seres humanos? ¿Tiene alguna actualidad el comunismo? ¿Cómo puede la obra poética de Roque Dalton aclararnos el sentido de muchas de estas preguntas? Bruno Bosteels, en el capítulo de su libro Marx and Freud In Latin America (2012), que le dedica a la última novela de José Revuelta Los errores y que titula "Marxism and Melodrama" afirma:

Para Revueltas, así como para alguien como Badiou, la tarea consiste en pensar los crímenes desde dentro de la propia tradición del comunismo, y no de un modo inverso, 
no se asume este gesto para estampar estos crímenes con la idea de la inevitabilidad histórica, sino para formular una crítica inmanente que a la vez evitaría el abandono del comunismo como tal. Lo que parece estar ocurriendo ahora, sin embargo, es una tendencia de interrumpir o peor aún, cerrar de forma anticipada cualquier proyecto emancipatorio radical en nombre de un imperativo moral nuevo que nos obliga sobre todo, sino de modo exclusivo, a prevenir la repetición del crimen. (Bosteels, 2012, p. 67)3

Concuerdo con la necesidad que propone Bosteels, siguiendo a Revueltas y a Badiou, de "pensar los crímenes desde dentro de la propia tradición del comunismo" y de no permitir, además, que ningún imperativo moral se use como justificación para ahogar el espíritu emancipador que visitó al continente latinoamericano en los años sesenta y que la obra de Dalton mantuvo vivo hasta su muerte. Sin embargo, la distancia que asumo tanto respecto a Badiou como a Bosteels tiene que ver con una diferente noción de la vanguardia y la relación que la misma tiene con el momento "estalinista" que vive todo socialismo real. Mi postura, y en eso creo que soy más fiel a Dalton, se encuentra mucho más cerca de la de Boris Groys que ve una continuidad, más que una ruptura, entre la vanguardia rusa y el período estalinista. Esto supone que se acepte tanto el lado más luminoso como el más oscuro de la total fusión entre la vida y el arte a la que aspiró la vanguardia y que acabó convirtiendo al comunismo de corte estalinista en la obra de arte total. Lo cual demuestra que no resulta tan fácil, como creía Walter Benjamin: "Así sucede con la estetización de lo político que propugna el fascismo. Y el comunismo le responde por medio de la politización del arte" (Benjamin, 2008, p. 85). Hay que aclarar, enseguida, que la politización de la estética que encarna el estalinismo, en la cual no está ausente la Revolución Cubana y sin la cual no se puede entender la obra de Dalton, se vincula a la noción de obra de arte total entendida como: "organización artística de la vida misma con arreglo a un único plan" (Groys, 2008, p. 62) y también: "organización directa de toda la producción y la vida cotidiana con métodos artísticos" (p. 63). Total fusión del arte con la vida, lo cual supone sacar al arte de sus marcos tradicionales: la obra, el museo, la contemplación, el goce de los sentidos; politizar de un modo radical el arte hasta borrar, como haría Dalton, cualquier distancia que lo pudiera separar del panfleto. Pero también significa asumir la vocación totalizante y totalitaria de la organización de lo real que comparten la obra de arte vanguardista y el 
momento estalinista que vive todo socialismo real, lo cual termina por convertir a la vida cotidiana en la obra vanguardista por excelencia, y termina por estetizar a lo político. Pensar el siglo XX y el legado del comunismo supone asumir ambas tareas, hacerse cargo de la continuidad que existe entre la inagotable promesa incumplida que todavía vive en la tradición marxista, y que en el arte se vive como una radical politización de la estética, y el posterior momento estalinista, la estetización de la política: el intento de convertir a la vida cotidiana en la obra de arte total $y$, con este objetivo, obligar a que los "materiales" que conforman la vida política y social se dobleguen ante un ideal, al costo que sea necesario, y se pongan en función de ese mismo ideal. Estos son el Dr. Jekyll y Mr. Hyde que nos legó la herencia marxista que se vivió en los socialismos "reales": el ruso, el chino, el coreano, el vietnamita, los de los países de Europa del este $y$, en caso de América Latina, la Revolución Cubana. Y para poder pensar este complejísimo legado sigue resultando imprescindible la obra de Roque Dalton.

Las dos figuras, entonces, a partir de las cuales me acercaré a la obra de Dalton y a esa promesa de emancipación radical que fue el comunismo, serán los de la herencia y de la promesa de felicidad que es todo futuro utópico. Ambas problemáticas serán leídas desde una perspectiva poética, pero no se debe olvidar que cuando digo poética me refiero a ese gesto total, anárquico que emprende el poeta al tratar de volver a fundar el mundo a través de sus palabras. Esa promesa se radicaliza, se hace incluso más adánica, cuando se pretende que esas palabras entreguen el mayor sentido de libertad y justicia que los humanos soñaron para su vida en común. Estos principios, en nuestro caso, serán personalizados a través de dos grandes figuras: Lenin y Antonio Gramsci.

Cualquier persona familiarizada con la obra de Dalton entenderá el porqué de la importancia de la primera figura, Lenin, debido a que Dalton le dedicó todo un libro al mismo, y su mención resulta constante a través de toda su obra. Más paradójico resulta la presencia de Gramsci. Hay solamente unas cuantas menciones de Gramsci en la obra en prosa de Dalton, y en un poema que es muy breve e irónico que citaremos más tarde. Para explicar la referencia a Gramsci quiero remitirlos a una entrevista que tuvo lugar hace muy poco; el 25 de mayo del 2015, en el programa Otra vuelta de tuerKa que dirige y conduce Pablo Iglesias, el líder del movimiento populista español Podemos. La entrevista era a Álvaro García Linera, actual vicepresidente de Bolivia, cuya relevancia política e intelectual para el mundo latinoamericano de hoy es conocida por todos. Hacia el final 
del programa, cuando Pablo Iglesias le preguntaba a su invitado sobre la opinión que le merecían revolucionarios como Gramsci y Lenin,
García Linera afirmó lo que en su opinión es la fórmula para tener éxito en un proceso revolucionario, aquí cito sus palabras:

En el fondo Pablo, la hegemonía es los dos. No es ni Lenin ni Gramsci. Articula, cambia el sentido común. Pero derrota al adversario. Y luego de derrotar al adversario se vuelve a rearticular. Gramsci solo no es suficiente, Lenin solo tampoco es suficiente. Hay que sumar Gramsci + Lenin + otra vez Gramsci, y esa es la fórmula real práctica de la hegemonía. Construcción cultural y articulación, derrota al adversario, nuevamente construcción y articulación del adversario derrotado, pero articúlalo nuevamente... (Iglesias, 25 de mayo del 2015)

Debido a las limitaciones de espacio en este ensayo, no puedo detenerme en la significación de estas palabras, lo que me interesa ahora es explicar brevemente por qué vincularé en este ensayo el problema de la herencia a la figura de Lenin y el del futuro a la de Gramsci. Como se verá enseguida, el gran tema del libro sobre Lenin que escribió Dalton es el problema de la herencia: ¿Cómo se hereda una tradición revolucionaria? ¿Cómo es posible el acceso a la tradición cuando la herencia automática a la misma está vedada? ¿Cómo se construye un legado revolucionario sin caer en la tentación de su monumentalización, su encierro dentro del dogma y las consignas? El futuro lo vincularé a Gramsci, debido a la importancia que ha adquirido su figura de la mano de pensadores como Ernesto Laclau y Chantal Mouffe en movimientos populares en Europa tanto como en América Latina: Tsiriza en Grecia, Podemos en España y Más en Bolivia. Los dos problemas, el de la herencia y el del futuro, están estrechamente vinculados entre sí. Ambos problemas, además, los interpretaré desde la noción que a los mismos les impone el lenguaje de Dalton. Así que no usaré el pensamiento de Lenin y Gramsci para interpretar la obra de Dalton. El movimiento será más bien el contrario, leeré la poesía de Dalton para interpelar a estas figuras y ver la validez que puedan tener para nuestra historia actual.

Empezaré entonces con la herencia y con Lenin, y luego pasaré al análisis del futuro donde Gramsci tendrá el rol protagónico. Se podría decir que la primera parte se enmarca dentro de la zona de estudios que ha dominado la crítica latinoamericana en los últimos años: el problema 
de la memoria, del duelo, de la difícil recuperación de un pasado traumático y la promesa, las posibilidades inéditas, que laten en todo pasado. En el caso de Dalton hay una novedad importante respecto a los estudios latinoamericanos, ya que el trabajo sobre el pasado no se hace solamente desde el duelo sino que la ironía ocupa un lugar central. La segunda parte será un poco a contrapelo respecto al tipo de estudios que han dominado a la academia en los últimos años. Pareciera que de tanto mirar al pasado nos hemos olvidado de interrogar al futuro. Y creo firmemente que no se puede rescatar una herencia revolucionaria si no se recupera ese gesto que es central en la tradición marxista. Para ser libres no resulta suficiente no olvidar: ser capaces de desentrañar las diferentes tramas que configuraron nuestro destino, que nos trajeron a donde estamos ahora. Para ser libres, hay que ser capaces también de interpelar al futuro, de arrancarle a esta tierra ignota que es todo porvenir, una promesa de un mundo mejor, más justo, y más vivible. Eso intentaré en la segunda parte del trabajo, y lo haré a través de un ejercicio contrafáctico, trataré de imaginar cómo hubiera reaccionado Dalton, su poesía, su obra, al giro hacia el populismo, vía Gramsci, y con la mediación de Chantal Mouffe y Ernesto Laclau, que ha tomado la izquierda en ambos lados del Atlántico: en Grecia, en España, en Bolivia, en Ecuador, entre otros.

\section{La herencia (Lenin)}

La herencia de una tradición en la modernidad es una tarea ardua. No se debe olvidar que lo moderno fue definido por Octavio Paz como el período donde la ruptura con todo lo anterior llegó a convertirla a ella misma en tradición. Tradición de la ruptura fue el término con que definió a la modernidad y a la vanguardia. ${ }^{4}$ Incluso, T. S. Eliot el poeta que afirmó que en el fin lo que encontramos es el principio, el origen, tuvo que reconocer que: "(la tradición) no puede heredarse, y quien la quiera, habrá de obtenerla con un gran esfuerzo" (Eliot, 1975 , p. 38. ${ }^{4}$ Hay que tener en cuenta que el término que usa Eliot en el original en inglés es "labor", que designa tanto el esfuerzo, el trabajo, como el acto de gestación. Heredar, para el poeta moderno, no es un acto pasivo y requiere trabajo, incluso la capacidad de crear, de reinventar el pasado. La dificultad de la tarea se agiganta cuando lo que se trata de heredar es el pensamiento, la obra del mayor revolucionario del siglo XX. El legado de un revolucionario que al decir de Toni Negri, uno de los responsables que el pensamiento de Lenin vuelva a ser escuchado en nuestro siglo, transmite un único y gran tema: 
Hablar de Lenin es hablar de la conquista del poder. Ya sea la posición que se asuma ante su obra de exaltación o de crítica, carece de sentido colocar a su obra en otro horizonte de sentido: la conquista del poder es el único tema leninista. (Negri, 2010, p. 285).

Las dificultades entonces se acrecientan, pues la pregunta ahora no es solamente cómo heredar una tradición revolucionaria sino también cómo se sitúa un poeta ante alguien cuyo principal propósito es tomar el poder. ¿ No debe la palabra poética, al menos eso nos enseñaba la tradición moderna, mantener una distancia crítica respecto al poder, a su conquista, ante los que tarde o temprano serán poderosos?
Para empezar a aclarar las muchas interrogantes que he dejado abiertas, creo que resultarán muy útiles las propias palabras que Dalton incluye en el prólogo del libro Un libro rojo para Lenin (2001). Este libro tuvo su origen en un poema "Para un poema en el centenario de Lenin", que Dalton publicó en un número especial de la Revista Casa de las Américas, en 1970 dedicado al centenario del revolucionario ruso. La cita en cuestión dice así:

Se trata de hacer un poema a Lenin y al leninismo para América Latina, que no sea un himno, sino un intento de, dijéramos, vivificación poética de su pensamiento revolucionario, que no sea un 'canto que se eleve al cielo', sino que sea 'entre otras cosas un canto', pero un canto que surja de las ideas, que sirva para poner estas ideas en renovado contacto con la tierra y los hombres. (Dalton, 2001, pp. 27-28)

La poesía para poder heredar el pensamiento revolucionario tiene que hacer dos cosas: facilitar el "viaje", la "traducción" de este pensamiento a América Latina y otorgarle nueva vida, vivificar este pensamiento, acercarlo a otras tierras y a otros hombres. Yo me centraré aquí en la segunda de estas tareas. Otorgarle una nueva vida al pensamiento de Lenin significa para Dalton en este libro, ser capaz de asumir una postura crítica ante el mismo. Ser capaz de escoger entre las diferentes potencias con las que este pensamiento imantó su momento histórico. La herencia nunca tiene un carácter único, el pasado siempre está constituido por múltiples temporalidades y uno tiene que escoger entre los múltiples espíritus y fuerzas que lo habitan. La herencia no es nunca un peso muerto ni un vínculo orgánico 
y natural con el pasado. Como se dijo anteriormente; se necesita un esfuerzo, un trabajo, el trabajo del duelo, que consiste en ser capaz de escuchar la posibilidad de una promesa, de un futuro latente, entre la algarabía de voces que vienen del pasado. Para poder heredar hay que ser capaz de criticar el pasado. Incluso, hay que negar ciertas porciones de él, y así poder recuperar la promesa de futuro que todo pasado esconde. Dice Dalton (2001), en el prólogo que venimos citando:

Independientemente de su estructura, la idea de este poema nació en mí como surgen todos los poemas para los poetas: como una necesidad expresiva acuciante. Esta necesidad fue estimulada muy particularmente por la polémica que se ha llevado a cabo en los últimos años sobre los problemas fundamentales de la revolución latinoamericana... que en el fondo ha sido, aunque muchas veces no se entendió así, una polémica sobre el leninismo. Esa polémica va alcanzando cada vez más niveles fructíferos, mayor madurez, pero su panorama reciente se caracterizó por una enorme confusión. Entre esta confusión y la ignorancia, Lenin fue invocado por todos los que discutían y muchos lo declararon de su exclusiva propiedad. Diversas interpretaciones antagónicas del leninismo han conseguido, en muchas ocasiones, alejarlo de su correcta aplicación latinoamericana. (p. 29)

El poeta se propone en este libro como el legítimo heredero del pensamiento de Lenin. Pero el hecho de concebirse como legítimo heredero, supone primero reconocer el carácter inaccesible del legado leninista: lo único que puede ser heredado de un legado revolucionario es su carácter utópico. La utopía, debido a su resistencia a ser reducida a una posesión concreta en un tiempo y un espacio específico, puede realizar el verdadero ideal de toda herencia revolucionaria: pertenecer a todos y por ende no ser patrimonio exclusivo de nadie. El Lenin que Dalton desea rescatar del pasado es el del gesto utópico, no el que llegó al poder durante la Revolución de 1917, sino el que soñó y luchó por un futuro que todavía no estaba al alcance de sus manos. Continúa Dalton (2001) en el prólogo ya citado:

Uso casi exclusivamente materiales escritos por Lenin antes de la toma del poder, durante la lucha concreta por el 
poder. Los únicos materiales escritos por Lenin después del 7 de noviembre (25 de octubre) de 1917 que utilizo, se refieren también directamente al problema de la toma del poder (...) El poema trata de dar una visión del Lenin de la toma del poder, del creador del leninismo como realizador en la historia de la previsión teórica de Marx. (p. 32)

Aquí encontramos la respuesta a la otra parte de la interrogante presentada antes: ¿Cómo se sitúa la palabra poética ante el gesto revolucionario por antonomasia: la toma del poder? ¿Cómo mantiene la palabra poética cierta distancia crítica ante la figura del revolucionario que se convertirá muy pronto en el detentador absoluto del poder? De Lenin, Dalton solamente escoge los textos que se relacionan con la lucha por la toma de poder; los textos que involucran la dimensión de potencia, de posibilidad inédita de futuro que tiene el poder y no su dimensión de razón de Estado. Y, además, siempre contrasta estos textos con la realidad latinoamericana actual. "No se trata -aclara Dalton- de comparar dos etapas históricas diferentes sino hacer una confrontación entre un pensamiento político universal y una realidad concreta" (Dalton, 2001, pp. 31-32). Esta tensión entre la vocación universal de la teoría marxista y la realidad concreta de este continente constituye una de las claves de lectura de este poema. Esta tensión dialéctica entre lo universal y lo concreto la propongo como una alternativa a las poéticas de lo local y/o lo global que asolan los discursos críticos ahora. De esta vocación universal del leninismo, Dalton salva la urgencia que acompaña a la lucha por la toma del poder. Pensar en la urgencia supone aceptar que, como bien aclara Žižek (2004) en su prólogo a la antología de textos de Lenin Revolution at the Gates: "la revolución no tiene un momento propicio... en lo que él (Lenin) insiste es que la excepción que representa la revolución ofrece una manera de socavar la misma norma" (p. 10). ${ }^{6}$

Pensar el lado urgente de lo universal supone pensar su lado de excepción, su suspensión de las normas. Es ese carácter universalexcepcional del pensamiento marxista el que articula Dalton en una relación dialéctica con la concreta realidad latinoamericana, entendida esta última como las condiciones materiales concretas que posibilitan la insurgencia en Latinoamérica, pero esta relación entre lo universal-excepcional y lo concreto no es sincrónica. Para poder enunciarla hay que poder crear una continuidad entre dos tiempos históricos que se caracterizan por su carácter intempestivo. El collage-poema que propone Dalton trabaja con diferentes temporalidades que niegan 
la linealidad del relato histórico. ¿Puede un escritor latinoamericano proponerse como legítimo heredero de esta vocación universalexcepcional del marxismo? Y si esto es posible, ¿bajo qué circunstancias? Ya que no hay un acceso inmediato a la herencia y ya que lo que define a la herencia como una substancia no se puede alcanzar, de esta manera hay que desplazar la pregunta del qué al quién. Dice Raymond Geuss, otro de los responsables del regreso de Lenin en la filosofía política actual, en su libro Philosophy and Real Politics:

Lenin define la política con la claridad y la concisión que lo caracteriza cuando dice que a la política le interesa la pregunta que recurre en nuestra vida política: ¿quién y para quién? Lo que esto significa en primera instancia es que las afirmaciones impersonales que uno estaría inclinado a hacer acerca de sociedades humanas requieren, si van a ser politicamente informativas, ser reelaboradas como afirmaciones acerca de gente real y concreta actuando sobre otra gente. (Geuss, 2008, p. 23-24) ${ }^{7}$

Geuss refina la reflexión leninista, y para él refinar quiere decir concretizar, del siguiente modo: "la fórmula no debe ser solamente ¿quién o a quién? si no ¿quién hace qué, para quién y en beneficio de quién" (Geuss, 2008, p. 25), ${ }^{8}$ con cuatro variables distintivas que deben ser rellenadas: 1. Quién, 2. Qué, 3. A quién, 4. Para quién. Pensar de forma política supone pensar acerca de la "agencia", "poder" e "interés" y la relación entre estas categorías. La ecuación que propone Dalton concretiza aún más este principio: quién hereda de quién, bajo qué circunstancias y dentro de qué parámetros lingüísticos, y en nombre o beneficio de quién. A las variables de "agencia", poder", e "interés" les añade Dalton las de "lugar", "lenguaje", "contexto" y "lugar de enunciación". La pregunta, además, se complica porque se hereda de un fantasma que es él mismo un heredero y a quien no se le permite que se convierta en estatua, en dogma.

El libro, Un libro rojo para Lenin, nos presentará entonces una larga saga de herederos legítimos: Lenin como heredero de Karl Marx, y por otro lado, Fidel Castro, Che Guevara, Ho-Chi Minh, Regis Debray, entre otros, como herederos de Marx y Lenin. Este linaje de herederos también incluye poetas: Maiakovsky, Otto René Castillo y el propio Dalton.

El concepto de legítima herencia está íntimamente ligado al de situación revolucionaria: luchar por tomar el poder desde un contexto específico, desde ciertas 
coordenadas espacio-temporales claramente definidas, por acceder a la dimensión de potencia, de posibilidad, de promesa de futuro que el poder contiene. Solamente en una situación revolucionaria se puede heredar la inclinación utópica del pensamiento marxista, pero el concepto de situación revolucionaria no únicamente afecta al contexto de recepción. El texto que se hereda tiene que haber sido producido también en una situación revolucionaria y requiere tener como uno de sus temas esenciales las condiciones necesarias para que este tipo de situación se produzca. El concepto de situación revolucionaria afecta tanto al contexto de producción y recepción del texto que el poeta desea transmitir como al propio texto transmitido.

Dalton escribe un libro que es a la vez un poema y un manual para guerrilleros porque nos enseña cómo heredar una situación revolucionaria y cómo incorporarla en un nuevo espacio y en un momento histórico diferente. Dalton nos obliga a plantearnos una serie de preguntas acerca de la relación entre la vanguardia política y estética: ¿Cómo escribir un libro que realmente funda la vida y el arte? ¿Cómo se puede transformar, del modo más literal posible, la pluma en un arma? ¿Para hacer esto es necesario, como hace Dalton, escribir un libro que pueda ser leído simultáneamente como un poemario y un manual para guerrilleros? O incluso mejor, ¿Cómo escribir un libro que pueda ser leído como un poema porque es un manual para guerrilleros o es un manual para guerrilleros debido a que es un gran poemario?

Decía André Breton que el acto verdaderamente surrealista era salir a la calle con una pistola y dispararle a la multitud. ${ }^{9}$ La idea de Breton es fácil de refutar. Si esta definición fuera cierta, casi todas las semanas la televisión nos entregaría el espectáculo de un artista surrealista que mata indiscriminadamente personas en la multitud. Lo extremo de esta concepción, sin embargo, es ilustrativa de dos factores-problemas que son esenciales para entender la inspiración vanguardista de la obra que estamos analizando: 1- ¿Cómo crear una obra que se funda totalmente con la vida vía la subversión de los códigos que organizan lo que entendemos como real?, 2- ¿Qué importancia tiene la violencia en esta concepción de la obra vanguardista y en su intento de insertarse en la realidad?

En su libro anteriormente citado Boris Groys afirma que: "El realismo socialista (como el arte Nazi, por ejemplo) se encuentra en la posición a la que la vanguardia aspiraba: fuera de los museos y la historia del arte y aparte de normas culturales tradicionales y socialmente establecidas" (Groys, B. (2008, p. 7). La virulencia y la subversión inherente a las formas 
de arte más panfletarias del siglo XX (y la paradójica relación de continuidad entre estas obras artísticas y la vanguardia) nos obligan a repensar muchos de los grandes tópicos de las vanguardias históricas y sus múltiples resurrecciones a lo largo del siglo XX: la supuesta radical ambigüedad de este tipo de arte, el predominio de la forma sobre el contenido, la distancia que se supone asumen frente a los discursos ideológicos dominantes y el supuesto carácter emancipatorio que tiene el intento de fusionar el arte y la vida.

La singular relación que tiene en la obra de Dalton la vanguardia política y artística nos obliga a redefinir los principios de ambas prácticas. En el caso de la vanguardia artística, Dalton cuestiona su supuesta radicalidad, su problemática relación con las masas, la relación entre lo individual y lo colectivo. En el caso de la vanguardia política, la coexistencia que se da en sus textos de un tono dogmático y satírico requiere una subversión del propio lugar de enunciación de lo político. Dalton, cuando trata temas políticos, nos recuerda a dos pensadores ilustrados, Ilámense Voltaire y Swift, que son en gran medida responsables de la incorporación del panfleto dentro de los géneros de la literatura moderna. Para estos autores, el panfleto es un lugar donde uno puede expresar un dogma político y a la vez hacer una sátira social. La coexistencia del dogma y la sátira causa una erosión en la rigidez y solemnidad del mensaje doctrinal. El Cándido de Voltaire es una sátira de una posición filosófica, la de Leibniz y Wolf que concibe a este mundo como el mejor de los mundos posibles, de una orden religiosa -de los jesuitas-, y a la vez es un panfleto político. Algo similar ocurre con el libro de Dalton, Un libro rojo para Lenin. Este poema-elegía para Lenin es un canto de elogio a una doctrina, a una idea revolucionaria, como también una reflexión irónica acerca de las diferentes asimilaciones que esta doctrina tuvo en el espacio postcolonial latinoamericano:

El poeta: - ...voy a defender una tesis, no original, por cierto... Yo, el poeta, soy en este caso y en general, el colonizado y la voz del colonizado. El colonizado que durante muchos años asumió como colonizado inclusive la teoría y la práctica revolucionarias. ¿Sería ir más allá de establecer un simple, aunque rotundo hecho histórico, el señalar que durante demasiado tiempo nos acercamos a Lenin con la ceguera del colonizado? Así, en una maroma histórica doblemente aplastante, la cultura del colonizador y la cultura revolucionaria de la humanidad más avanzada... 
fue para nosotros carne y bocado de enajenación, aunque en distintos niveles. Eso, sin decir que hubo también una corriente muy conocida en el campo revolucionario mundial, que cristalizó en dogmas el pensamiento marxistaleninista. En la tarea de búsqueda de nuestra identidad y del rescate de las armas revolucionarias del arsenal de la experiencia histórica de los pueblos, los poetas colonizados-pero-en-proceso-de-descolonización aportamos una actitud social concreta y un tipo concreto de lenguaje. Eso que usted identifica por un 'tonillo zumbón', por un 'distanciamiento irónico', es simplemente lo que ya alguien ha llamado el lenguaje crítico. Dentro de este lenguaje, las actitudes al parecer irreverentes no son una bufonada más, una 'mueca para hacerse agradable al blanco' sino una legítima arma de defensa objetivada en dicho lenguaje. Como ha dicho alguien: 'la ironía del colonizado desacraliza los valores de la cultura sobreimpuesta (la del colonizador, la cultura revolucionaria ajenada por el dogma y sus diferentes registros, etc.) y la problematiza con sus mismos elementos'. Los subrayados, no son solo irónicos, sino míos ¿Me explico? (Dalton, 2001, pp. 128-30)

La dialéctica de la herencia en Dalton combina el trabajo del duelo con el trabajo de la ironía. La ironía impone una distancia entre el signo y su significado, entre la intención del hablante y su discurso, lo cual introduce una radical ambigüedad dentro del discurso político. La ironía produce una ruptura, un hiato entre la obra y su audiencia, entre la palabra y la praxis.

La ironía, el tono zumbón, es la forma en que Dalton se sitúa a sí mismo ante esta herencia, este legado, ante el espíritu de la tradición revolucionaria. En este libro se trata de reorientar este espíritu, el de Lenin, el de la revolución; contaminarlo, hacerlo que recorra itinerarios desconocidos, que hable con otro lenguaje.

Las dos estrategias retóricas que Dalton emplea para asimilar de un modo crítico e irónico el legado revolucionario son: la apropiación y la traducción. Este libro es también un collage donde los límites entre la voz del propio autor y de las fuentes citadas se desdibujan, donde los límites entre escritura y lectura desaparecen. Muchos de los textos que el poema presenta son fragmentos de traducciones de clásicos del marxismo. Encontramos textos de Engels, Lenin, Trotsky, Lukács y también de Ho Chi Minh, Ernesto "Che" Guevara y Fidel Castro. Este libro presenta fragmentos que han 
sido compilados y traducidos de diversas lenguas por el autor. En su caso, asimilación y traducción no significan fidelidad al original, más bien suponen una reinvención, reapropiación del mismo. De esta forma es que se debe entender la cita anterior que proponía un desplazamiento de la figura del poeta latinoamericano del colonizado al colonizador. El poeta es un singular tipo de colonizador que no impone su modelo sobre otros sino que se apropia, traduce, roba de otras tradiciones y escribe, crea y produce a partir de la reinvención de estas tradiciones. La mejor manera de continuar una tradición es romper con ella, subvertirla, traicionarla y escribir libros rojos, que reinventen, subviertan y traicionen a sus modelos.

Pero lo que distingue a este desvío, reinvención, subversión de la tradición, en el proyecto de Dalton es el tono zumbón: la distancia entre la palabra y sus contextos de enunciación, esta nueva forma de heredar vía la ironía; en un texto donde la distancia que existe entre literatura y política, poesía y panfleto literario ha sido reducida al mínimo. Lo que hay que enfatizar es el singular trabajo que hace la ironía cuando un texto de carácter ideológicopropagandístico es asumido dentro de los confines de la palabra poética. Por ejemplo, en su libro Taberna y otros lugares, Dalton incluye un poema titulado "Sobre dolores de cabeza" que dice: "El comunismo será, entre otras cosas, / una aspirina del tamaño del sol" (Dalton, 2000, p. 119). Este versopanfleto-proclama es también un verso irónico. La radical naturaleza del proyecto poético de Dalton reside en su capacidad de combinar el carácter performativo-exhortativo de la proclama con la absoluta e infinita negatividad de la ironía. ${ }^{10}$ Este verso puede ser leído de tres maneras diferentes: en la primera, uno puede asumir que el comunismo es la medicina que viene a curar todos los males. Una segunda lectura, también legítima, afirmaría que el comunismo alivia todos los males pero no cura ninguno. El novelista cubano, Leonardo Padura, en su novela Pasado perfecto, propone incluso una tercera lectura que sugiere los ecos que este verso pudo tener en Cuba: “¿Qué quiere decir este lema 'que el comunismo es una aspirina del tamaño del sol'?... no querrá decir esto que el Socialismo es un gran dolor de cabeza que el comunismo tiene que curar" (Padura Fuentes, 2000, p. 59). La radical ambigüedad que la ironía introduce dentro del slogan permite que se lea de una forma que puede contradecir la intención original de su autor. No se puede decidir entre los tres significados contradictorios de la frase, ni tampoco se puede afirmar con certeza cuál fue la intención original del autor. 
La ironía en el caso de Dalton, nos sirve para detectar la particular inflexión que él le quiere dar a la figura del poeta guerrillero, del poeta comprometido, la relación que él intenta proponer entre la literatura y el arte, entre la poesía y la política. Dalton intenta construir una distancia entre el lenguaje literario y el político, un espacio líricosubjetivo, en un libro que parece borrar las fronteras que separan el arte de la vida. Deja que la palabra poética se queme en la consigna panfletaria, se confunda con el panfleto. Pero a la vez exorciza con igual fuerza a los slogans que quieren enmascararse como palabra poética. Mantiene intacta la invitación y la advertencia de Walter Benjamin: politizar lo estético, condenar toda estetización de la política. Ejemplar en este sentido, y digno de mención por la influencia que tuvo en los estudios literarios y culturales, fue el slogan: "I like Ike" de Eisenhower y que Roman Jakobson convirtió en la figura emblemática de la función poética del lenguaje. El gesto de Jakobson convierte a todo enunciado, y en especial al político, en una subespecie del lenguaje poético. Totalmente contraria a esta tendencia es la posición que defendemos aquí, inspirados por la obra de Boris Groys, que descubre una zona de total contacto-porosidad entre la obra de arte y el panfleto, y se ve una línea de continuidad entre los proyectos de vanguardia y el arte panfletario del período estalinista.

\section{La promesa (Gramsci)}

En esta segunda parte de este estudio, Antonio Gramsci, como lo fue Virgilio para Dante, será mi guía hacia lo ignoto. El guía hacia el lugar donde la recta vía se pierde. El propio Dalton en Un libro levemente odioso asocia a Gramsci con lo intempestivo, ${ }^{11}$ con un futuro que solamente será concebible si saca al presente de sus quicios, si perturba los diferentes regímenes discursivos con que organizamos la realidad. En ese libro incluye un poema muy breve e irónico que dice "Qué le dijo el movimiento comunista internacional a Gramsci": "No tengo edad/no tengo edaaaad, para amarte..." (Dalton, 2004, p.
57). Si le creemos a Chantal Mouffe y a Ernesto Laclau nuestra época ya ha alcanzado la edad para amarlo y la supervivencia de ese sueño emancipador que se mencionó al principio de este texto, el comunismo, depende en gran medida de Gramsci y de su concepto de hegemonía. No es casualidad que en los Diálogos de invierno 2015 planteados por la Secretaría de Arte y Cultura del FMLN, se haya propuesto el tema "Hegemonía para un cambio social". Vale la pena entonces que nos detengamos un minuto a delinear algunos rasgos de este concepto, hegemonía, y luego ver la productividad que ese mismo 
tiene para responder las preguntas que nos impone nuestro tiempo y ver su pertinencia para leer ciertas zonas de la obra de Dalton, en particular su libro Las historias prohibidas del pulgarcito.

Me apresuro a aclarar que no pretendo agotar todos los matices de este complejísimo concepto y que me limitaré a delinear algunos de los rasgos que ha adquirido a partir de la recuperación que han hecho Ernesto Laclau y Chantal Mouffe en su libro Hegemonía y estrategia socialista y Ernesto Laclau en La razón populista. EI protagonismo que le otorgo a estas lecturas del concepto gramsciano de hegemonía sobre otras se debe a la inmensa repercusión que estos libros han tenido en la nueva izquierda latinoamericana y europea. La pregunta que ha guiado mi reflexión, los problemas inherentes a la herencia y al futuro del mayor proyecto emancipador que han imaginado los seres humanos y del proyecto intelectual de Dalton, justifica esta elección.

Empiezo con una cita del propio Gramsci del volumen II de sus Cuadernos de la cárcel:

Un acto histórico sólo puede ser llevado a cabo por el 'hombre colectivo', y esto presupone el logro de una unidad 'cultural-social' a través de la cual una multiplicidad de voluntades dispersas, con objetivos heterogéneos, son soldadas en torno a un único objetivo sobre la base de una común e igual concepción del mundo (...) (Gramsci citado por Laclau y Mouffe, 1987, p. 118).

De esta cita se pueden derivar muchos de los rasgos esenciales del concepto de hegemonía:

1. Los sujetos políticos son pensa dos, desde esta categoría, no como clases sociales sino como voluntades colectivas que tienen un carácter fragmentario y heterogéneo. Esto supone un cambio radical respecto al marxismo tradicional; no existe una relación necesaria entre la posición que se ocupa en las relaciones de producción y los objetivos emancipadores que puedan tener ciertos actores sociales. El significado político de un movimiento depende de la articulación hegemónica dentro de la cual se inserte. ${ }^{12}$

2. La identidad de los actores sociales se configura alrededor de los reclamos-demandas que ellos le hacen al sistema y debido a la incapacidad que él tiene de suplirlas, así se crea una homologación entre diferentes demandas heterogéneas lo que configura un reclamo que se reúne alrededor 


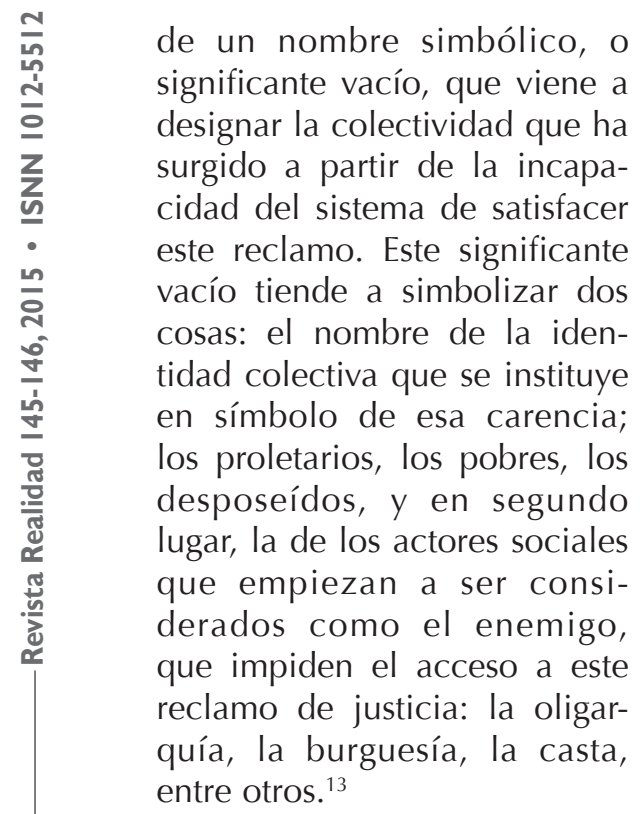

3. Cuando el reclamo desborda las instituciones que pueden satisfacer estas demandas se configura la figura del "pueblo"14 que requiere una reestructuración total del orden simbólico existente para que estos reclamos puedan ser respondidos. El "pueblo" se convierte entonces en el significante maestro, en el símbolo de un exceso: una zona de lo común ${ }^{15}$ que no es reconocible dentro de las diferentes esferas discursivas existentes, una zona de lo común que excede los sentidos considerados legítimos por un orden existente. ${ }^{16} \mathrm{EI}$ "pueblo" acopla a todos los actores sociales que emergen contra el status quo.
Si las tramas del pasado, el drama de la herencia, nos enfrentaba a la porosidad que yuxtaponía la obra de arte total y el sentido totalitario de lo social, las preguntas por el futuro vendrán acompañadas por otros dilemas. Las aporías de la herencia las ventilamos con la lectura de Un libro rojo para Lenin, las del futuro, como ya se adelantó, con Las historias prohibidas del pulgarcito. Las preguntas-dilemas que este libro nos propone son las siguientes: ¿Cómo se construye el sujeto colectivo del pueblo si no se aceptan los instrumentos pedagógicos, políticos y cívicos que la comunidad nacional implementa para su constitución? ¿Qué espacio, qué lugar, qué agencia les corresponde a todos aquellos cuyos reclamos y demandas no son satisfechos ni reconocidos por las instituciones que configuran la realidad política de una nación? ¿Qué parte le corresponde a todos aquellos que no son incluidos en el orden existente, qué parte, como decía Rancière, les corresponde a los sin parte? ${ }^{17}$ ¿Cómo nombrar esa zona de lo común, de lo colectivo, que ha sido expulsada de todas las esferas discursivas, esa zona de lo común para lo cual no encontramos ningún sentido inteligible, ninguna zona de legitimidad? ¿Qué hay que hacer para crear una nueva relación entre el sentido y esas zonas de lo común que han sido excluidas de toda normatividad, para reinventar el sentido común? 
El libro de poemas Las historias prohibidas del pulgarcito también es un libro-collage, un poema-objeto. A través de este poema-collage hecho de textos históricos, reales y apócrifos, poemas y bombas, se cuenta de un modo tragicómico la historia nacional. Existen varios estudios críticos ${ }^{18}$ que se han dedicado a analizar cómo estos diferentes fragmentos, y la variedad textual que ellos representan, cuentan la historia silenciada de la nación. Mi lectura sin dejar de reconocer la importancia -como se ha insistido en la crítica- que tiene la parodia y deconstrucción de la historia nacional y la genealogía que este libro propone de un imaginario subversivo y revolucionario, pone el énfasis en otros aspectos que también me parecen centrales en el libro: el cuestionamiento y la destrucción del mito fundacional del patriotismo, el amor por el lugar de origen, el amor a la patria, y la construcción de una noción de "pueblo" a contrapelo de todas las mitologías nacionalistas y de la concepción marxista de clase social. La noción de "pueblo" que se maneja en Las historias prohibidas del pulgarcito excede a la noción de clase que asociamos con el marxismo clásico. En este libro, vía el uso del collage, escuchamos diferentes voces de ese "pueblo" al que interpela el autor en todas sus páginas: el líder indígena Anastasio Aquino, el líder centroamericano Francisco Morazán, el líder nacional Gerardo Barrios, el pueblo indígena que lleva la guerra de guerrillas en su sangre desde la época de la conquista y de la subyugación española bajo Alvarado, la voz popular de los refranes, las bombas, y las canciones indígenas, entre otros. Lo popular se dice de muchas maneras; muchas de ellas no reducibles a conflictos económicos o de clase.

El primer texto del libro es un extracto de una carta escrita por Pedro de Alvarado a Hernán Cortés describiéndole su primera derrota en la tierra de Cuzcatlán. Este primer fragmento cumple dos roles: como un texto fundacional y como principio de la genealogía del concepto de "pueblo" que este texto quiere proponer. Ambos roles están estrechamente relacionados entre sí. Esta carta de Alvarado es el texto fundacional porque es a partir de él que se empieza a configurar la noción de "pueblo" que Dalton quiere proponer en este libro; la identidad popular no tiene existencia previa a la existencia de un enemigo. La unidad es solamente concebible, como insiste Laclau recordando a Saint-Just, a partir de la destrucción de lo que se le opone. ${ }^{19}$ En la estructura antagónica que configura todo espacio social, la presencia del otro-enemigo impide a las identidades sociales completarse, ser totalmente ellas mismas. La imposibilidad de ser una comunidad plena, cerrada, de ser, en el caso que nos concierne, una tribu, una etnia, una nación es lo que nos constituye como pueblo. 
Como ya se dijo, el "pueblo" supone un exceso de lo común que no resulta articulable dentro de las estructuras de sentido reconocibles en cierto momento histórico, como añado ahora, ese exceso, esa imposibilidad de entender lo social como un espacio cerrado siempre es producto de un antagonismo. Las primeras identidades populares que postula el libro se configuran desde la lengua del enemigo: los indígenas guerrilleros para Alvarado, los indios brujos para los curas. Estas identidades incluso pueden tener un carácter ficticio. La construcción de "pueblo" se concibe en el libro de dos modos: como una serie de cesuras en el discurso dominante y por la emergencia de una serie de voces que han sido silenciadas por la historia oficial. La censura implementada sobre las historias prohibidas del relato nacional y la cesura que se deja escuchar a través de las grietas del discurso oficial configuran los rasgos de esa entidad que será nombrada -en uno de los poemas centrales del libro- con el significante vacío de "pobres".

Junto a esta articulación de la identidad popular vía la agresión física y simbólica del enemigo, Dalton procede a desmontar todos los mitos a partir de lo cual se configura el amor a la patria. En uno de los primeros fragmentos titulado "Paisajes y hombres" se describe el territorio nacional no como ese espacio idílico que provoca la nostalgia de los poetas románticos y costumbristas, sino como una tierra hostil, inhabitable. El narrador caracteriza al territorio nacional como "una tierra enferma" y procede a describir todos los insectos, criaturas venenosas y todos los peligros que rodean al hombre en una tierra como esta. En otro fragmento, donde se hace referencia al Himno Nacional con "Saludemos la patria orgullosos de hijos suyos podernos llamar", se contrasta este juramente vacuo y pomposo a la patria con la historia de una familia que caminó tres mil kilómetros con la esperanza de hacerse ciudadana americana y que terminó siendo detenida por las autoridades migratorias. ¿Cómo se puede amar a una tierra donde las posibilidades de morir de hambre son mucho más altas que las de asistir a la escuela? No se debe olvidar el epígrafe de Lawrence Durell que Dalton incluye en su novela Pobrecito poeta que era yo: "Es una obligación de todo patriota odiar a su país de una manera creadora" (Dalton, 1994, p. 11). Y es ese odio creador, que tiene una función similar a la que cumplía la destrucción-creadora en Un libro rojo para Lenin, el que se coloca en el origen de la constitución del "pueblo", tal y como lo concibe este poemario.

Detengámonos ahora en el que, sin duda, es el poema más conocido de este libro, y de toda la obra de Roque Dalton, al menos en El Salvador: "Poema de amor". 
Este poema ha llegado a representar para muchos un segundo himno nacional. Sin embargo, si se lee con cuidado este poema, notamos que está inscrito en una de las secciones del libro donde el collage, entendido como aparato retórico que desmonta el relato clásico de lo nacional, tiene una mayor presencia. La sección del libro donde encontramos "Poema de amor" se titula: "La guerra es la continuación de la política por otros medios y la política es solamente la economía quintaesenciada". Este bricolaje que crea Dalton entre Clausewitz y Marx explicita una noción de antagonismo que supera la geografía conceptual marxista del conflicto de clase. En este fragmento se recrea la mal llamada "guerra del fútbol" en la que se luchó alentando, de modo chovinista, el sentimiento patriótico de los salvadoreños y hondureños. Dalton muestra a través de varios fragmentos de periódico y de sus propias reflexiones cómo el amor por la patria es usado tanto por El Salvador y Honduras para crear una guerra cuyo único objetivo era producir una falsa unidad nacional y distraer a estas poblaciones de sus reales problemas.

El "Poema de amor" funciona en el libro, entonces, no solamente como una celebración de la patria sino como una demostración de las esquinas miserables y oscuras de la realidad salvadoreña. Únicamente a través de las hostiles y precarias condiciones que crea la historia salvadoreña se puede nombrar, más allá de todos los ritos patrióticos, al pueblo. Únicamente a través del odio creativo se puede reinventar la filia, el sentido de pertenencia. La articulación contrahegemónica ${ }^{20}$ que posibilita la postulación del significante maestro, "pueblo", se hace con esa modalidad afectiva, el odio creativo, que invierte el topos fundacional de todas las mitologías nacionales: el amor a la patria. La construcción de una contrahegemonía conlleva un trabajo sobre los afectos, sobre el pathos que configura los sujetos colectivos. ${ }^{21}$ Lo singular del trabajo afectivo que propone Dalton es que coloca el énfasis en la necesidad de disolver las configuraciones colectivas que postula el imaginario nacional, de ahí la centralidad que se le da al odio como antídoto a la filia por el origen, por la tierra natal, para poder configurar nuevas sujetos colectivos trasnacionales designados por significantes que explicitan su precariedad y carencia. Como veremos enseguida, el significante que Dalton opone a los dos sujetos nacionales enfrentados en "la guerra del fútbol", los salvadoreños y hondureños, es el significante vacío "pobres". La fuerza de este significante es que define a la colectividad que nombra no por sus rasgos históricos, nacionales, culturales, de clase, entre otros., sino que la designa a partir de su propia precariedad en la cadena simbólica y de poder a la cual pertenece. 
El "pueblo" como entidad se configura a partir de una serie de exclusiones, de negaciones, de marginaciones, y de explotación: "los que se pudrieron en la cárceles de Guatemala, México, Honduras, Nicaragua, / por ladrones, por contrabandistas, por estafadores, por hambrientos, los siempre sospechosos de todo" (Dalton, 2002, p. 200). Este pueblo se define no tanto por su unidad, sino por esa regularidad que otorga la dispersión, tal y como definía Foucault las unidades discursivas, ${ }^{22}$ de haber sido expulsado de todo, de haber sido negados por todo. Como ya he repetido varias veces en este texto; el "pueblo" se funda cuando hay cierta forma de lo común que desborda todas las formas de normatividad reconocibles en un momento histórico determinado. Solamente cuando se desnudan los mitos de la historia nacional, cuando se destruye su encantamiento, surge el real sujeto de la historia: los pobres, el "pueblo". Es un sujeto desnudo, anónimo, que vive atravesando fronteras, que únicamente se le puede ver cuando se destruye la ilusión de la nacionalidad. Dalton, en el último fragmento de esta sección que titula "Algunos resultados del conflicto (hasta la fecha)" resume el sentido que tuvo para él la mal llamada "guerra del fútbol", lo dice mucho mejor que yo:

Decenas de miles de salvadoreños vagando con su hambre a cuestas, de Honduras a El Salvador y de El Salvador a Honduras. En Honduras ya no tienen tierra, en El Salvador no tienen tierra ni trabajo. No son ni salvadoreños ni hondureños: son pobres. (Dalton, 2002, p. 215)

La localización de este sujeto se define por la universalidad de la condición que explicita su falta. ${ }^{23}$ Este sujeto carece de los dos significantes maestros que configuran y localizan, anclan, en un territorio y una historia concreta, a casi toda identidad: la tierra (la nación, la cultura, la etnia, la lengua) y el trabajo (el dinero, la propiedad, el sitio que se ocupa en la cadena de producción, el poder). El que ellos existan sin tierra ni trabajo, desplazados fuera y dentro de sus fronteras, es lo que los engloba bajo el significante vacío de "pobres". Pero es este significante vacío lo que les otorga una nueva localización asentada en la universalidad de la falta que los designa. El "pobre" es el significante que designa a todos aquellos que tienen carencias fundamentales, sean tales de carácter económico, político, simbólico, espiritual o una mezcla de todas ellas. El carácter heterogéneo de las múltiples demandas de los sujetos que configuran este grupo queda subsumido en ese emblema de la carencia universal 
que es el significante "pobre". ${ }^{24}$ Es este exceso significacional que desborda las formas de lo común cartografiadas por los espacios discursivos hegemónicos (en este caso concreto, los sujetos nacionales salvadoreño y hondureño y el falso antagonismo que desplegó "la guerra del fútbol") lo que convierte a los "pobres" en el nuevo sujeto popular: portador de una nueva forma de antagonismo y de hegemonía dentro del relato emancipatorio que cuenta, compone, canta y piensa un libro como Las historias prohibidas del pulgarcito. La trascendencia de Dalton en el siglo XXI dependerá, en gran medida, de los dividendos que esta fórmula de convivencia musical, verbal y política tenga para el siglo que apenas empieza. La obra de Dalton para poder atravesar todos los largos años que le quedan al siglo en que vivimos tendrá que ser capaz de encarnar la inactualidad inherente al comunismo, cuya modalidad temporal es siempre intempestiva; pensar, cantar, soñar e ironizar sobre el comunismo como herencia y como promesa.

\section{Referencias}

- Benjamin, W. (2008). La obra de arte en la época de su reproductibilidad técnica. En Obras Libro 1/vol .2 Madrid, España: Abada Editores.

- Bosteels, B. (2012). Marx and Freud in Latin America: Politics, Psychoanalysis, and Religion in Times of Terror. New York, USA: Verso.

- Dalton, R. (2004). Un libro levemente odioso. San Salvador, El Salvador: UCA, Editores.

- . (2002). Las historias prohibidas del pulgarcito. San Salvador, El Salvador: UCA, Editores.

- (2001). Un libro rojo para Lenin. San Salvador, El Salvador: UCA, Editores. . (2000). Taberna y otros lugares. San Salvador, El Salvador: UCA, Editores. UCA, Editores. (1994). Pobrecito poeta que era yo. San Salvador, El Salvador:

- Eliot, T. S. (1975). Tradition and the Individual Talent. En F. Kermode. (Ed.), Selected Prose of T.S. Eliot (pp. 37-44). New York, USA: Harcourt Brace.

- Errejón, I. y Mouffe, C. (2015). Construir pueblo. Barcelona, España: Icaria. 
- Foucault, M. (2008). La arqueología del saber. Madrid, España: Editorial Siglo XXI.

- Galeano, E. (1993). El libro de los abrazos. Madrid, España: Siglo XXI.

- Iglesias P. (25 de mayo del 2015). Entrevista a Álvaro García Linera. Otra vuelta de tuerKa (programa de televisión.), España. Recuperado de https://youtu.be/a0mPTnNrovU

- Geuss, R. (2008). Philosophy and Real Politics. Princeton, USA: Princeton UP.

- Groys, B. (2008). Obra de arte total Stalin. (Trad. Desiderio Navarro). Valencia, España: Pre-textos.

- Laclau, E. (2005). La razón populista. (Trad. Soledad Laclau). México: Fondo de Cultura Económica.

- _ (1993). Nuevas reflexiones sobre la revolución de nuestro tiempo. Buenos Aires, Argentina: Ediciones Nueva Visión.

- Laclau, E. y Mouffe, C. (1987). Hegemonía y estrategia socialista. Hacia una radicalización de la democracia. Madrid, España: Editorial Siglo XXI.

- Negri, T. (2010). Qué hacer hoy con ¿Qué hacer?, o el cuerpo del general intellect. En S. Budgen, et. al. (Eds.), Lenin reactivado. Hacia una política de la verdad. Madrid, España: Akal.

- Padura Fuentes, L. (2000). Pasado perfecto. Barcelona: Tusquets.

- Rancière, J. (1996) El desacuerdo. Política y filosofía. (Trad. Horacio Pons). Buenos Aires, Argentina: Ediciones Nueva Visión.

- Žižek, S. (2004). Revolution at the Gates. London, England: Verso.

\section{Observaciones:}

En este trabajo aparece el apellido Žižek (las marqué en pág. 10, en la nota 5 , y en las referencias), pero en el documento de Julio Flores se refiere como Zizek. Por lo que dejo a su criterio si sería conveniente estandarizarlo. 
1. Conferencia de Clausura del V Congreso Centroamericano de Estudios Culturales, dictada en el Auditorio Segundo Montes de la Universidad Centroamericana José Simeón Cañas, el 22 de julio de 2015 .

2 Para leer la entrevista completa realizada a Jorge Luis Borges, consultar la dirección: http://www.arquitrave.com/ entrevistas/arquientrevista_jborges. html

3 A menos que se indique lo contrario, todas las traducciones pertenecen a la autora, y para mayor claridad se coloca en algunas notas el texto original en inglés. "For Revueltas, as for someone like Badiou, the task consists in thinking the crimes from within the politics of communism, and not the other way around -not so as to ratify the facts with the stamp of historical inevitability, but so as to formulate an immanent critique that at the same time would avoid the simple abandonment of communism as such. . . . What seems to be happening today, however, is a tendency to interrupt or, worse, to foreclose in anticipation any radical emancipatory project in the name of a new moral imperative ... which obliges us above all, if not exclusively, to avoid the repetition of the crime" (Bosteels, 2012, p. 67)

4 Para un estudio más detenido de la tradición en Paz véase Los hijos del limo, publicado originalmente en 1973

5 "(tradition) cannot be inherited, and if you want it you must obtain it by a great labour" (Eliot, 1975, p. 38).

6 "revolution has no 'proper time'. . . what (Lenin) insists on is that the exception... offers a way to undermine the norm itself" (Žižek, 2004, p. 10).
7 "Lenin defines politics with characteristic clarity and pithiness when he says that it is concerned with a question that keeps recurring in our political life: "Who whom?" (TO $\underline{\mathrm{KO}} \underline{\underline{\mathrm{O}}})$ What this means in the first instance is that the impersonalised statements one might be inclined to make about human societies generally require, if they are to be politically informative, elaboration into statements about particular concrete people doing things to other people" (Geuss, 2008, pp. 23-24). “(...) the formula should read not merely 'Who whom' but, rather, Who $<$ does $>$ what to whom for whose benefit" with four distinct variables to be filled in, I.E., 1-Who? 2-What? 3- To Whom, 4-For whose benefit? To think politically is to think about agency, power, interes, and the relations among these" (Geuss, 2008, p. 25).

9 Véase el Primer Manifiesto Surrealista en: https://docs.google. com/file/d/0B6ooguVRc_OVUZIVU5rZFdzZFE/ edit

10 Para leer más sobre el concepto de ironía revisar el libro de Soren Kierkegaard, Sobre el concepto de ironía, publicado primigeniamente en 1841.

11 Para una recuperación del concepto de lo intempestivo, de origen nietzscheano, para el contexto latinoamericano ver The Untimely Present. Postdictatorial Latin American Fiction and the Task of Mourning, de Idelber Avelar.

12 "Ni los sujetos políticos son para Gramsci 'clases' -en el sentido estricto del término-, sino 'voluntades colectivas' complejas; ni los elementos ideológicos articulados por la clase hegemónica tienen una pertenencia de 
clase necesaria (...) Respecto al primer punto, la posición de Gramsci es clara: la voluntad colectiva resulta de la articulación político-ideológica de fuerzas históricas dispersas y fragmentadas. $\mathrm{O}$ sea, que la equivalencia es siempre hegemónica en la medida en que no establece simplemente una 'alianza' entre intereses dados, sino que modifica la propia identidad de las fuerzas intervinientes en dicha alianza. Para que la defensa de los intereses de los obreros no se haga a costa de los derechos de las mujeres, de los inmigrantes o de los consumidores, es necesario que se establezca una equivalencia entre estas diferentes luchas" (Laclau y Mouffe, 1987, p. 118).

13 “(...) presencia de algunos significantes privilegiados que condensan en torno de sí mismos la significación de todo un campo antagónico (el 'régimen', la 'oligarquía', los 'grupos dominantes' (...) para el enemigo; el 'pueblo', la 'nación', la 'mayoría silenciosa' (...) para los oprimidos -cuales de estos significantes van a adquirir un rol articulador va a depender, obviamente, de una historia contextual” (Laclau, 2005, p. 114).

14 "Aquí tendríamos, por lo tanto, la formación de una frontera interna, de una dicotomización del espectro político local a través de una cadena equivalencial de demandas insatisfechas. Las peticiones se van convirtiendo en reclamos. A una demanda, que satisfecha o no, permanece aislada, la denominaremos demanda democrática. A la pluralidad de demandas que, a través de su articulación equivalencial, constituyen una subjetividad social más amplia, la denominaremos demandas populares: comienza así, en un nivel muy incipiente, a construir al 'pueblo' como actor histórico potencial. Aquí tenemos, en estado embrionario, una configuración populista” (Laclau, 2005, p. 99).

15 "Para que haya una 'equivalencia democrática' es necesario algo distinto: la construcción de un nuevo 'sentido común' que cambie la identidad de los diversos grupos, de tal modo que las demandas de cada grupo se articulen equivalencialmente con las de los otros, en palabras de Marx: 'que el libre desarrollo de cada uno sea la condición para el libre desarrollo de todos los demás" (Laclau, 2005, p. 303).

16 "Hay una plenitud de la comunidad que está ausente. Esto es decisivo: la construcción del 'pueblo' va a ser el intento de dar un nombre a esa plenitud ausente. Sin esta ruptura inicial en el orden social (...) no hay posibilidad de antagonismo, de frontera o, en última instancia, de 'pueblo"' (Laclau, 2005, pp. 112-13).

17 La cita completa de Rancière incluida en su libro El desacuerdo, dice así: "Lo que no tiene parte -los pobres antiguos, el tercer estado o el proletariado moderno- no puede, en efecto, tener otra parte que la nada o el todo. Pero también es a través de la existencia de esta parte de los sin parte, de esa nada que es todo, que la comunidad existe como comunidad política, es decir dividida por un litigio fundamental, por un litigio que se refiere a la cuenta de sus partes antes incluso de referirse a sus 'derechos'. El pueblo no es una clase entre otras. Es la clase de la distorsión que perjudica a la comunidad y la instituye como 'comunidad' de lo justo y de lo injusto" (Rancière, 1996, p. 23).

18 Algunos de los trabajos críticos que estudian este tema más a fondo son el artículo de Leonel Menéndez "Las historias prohibidas", la tesis de Máster de Edil González-Carmona La función 
ideológica de la técnica 'collage' en Las historias probibidas del Pulgarcito de Roque Dalton y el artículo de Jorge Narváez "El sentido de la intertextualidad en Las historias probibidas del Pulgarcito".

19 "Según dijera Saint-Just: 'Lo que constituye la unidad de la República es la destrucción total de aquello que se opone a ella"' (Saint-Just citado por Laclau, 1993, p. 38).

20 "El otro concepto clave es el de hegemonía, porque pensar lo político como posibilidad siempre presente del antagonismo requiere admitir la falta de fundamento último y reconocer la dimensión de indecidibilidad y contingencia que le impregna todo orden. En nuestro vocabulario requiere admitir la naturaleza hegemónica de todo orden social que es el producto de una serie de prácticas que intentan establecer un orden en un contexto de contingencia (...) Por eso afirmamos que todo orden hegemónico puede ser transformado por prácticas contrahegemónicas que van a tratar de instalar otra forma de hegemonía”. (Errejón, y Mouffe, 2015, pp. 13-14).

21 "No hay populismo sin una investidura afectiva en un objeto parcial. Si la sociedad lograra alcanzar un orden institucional de tal naturaleza que todas las demandas pudieran satisfacerse dentro de sus propios mecanismos inmanentes, no habría populismo pero, por razones obvias, tampoco habría política. La necesidad de constituir 'un pueblo' (una plebs que reivindica ser un populus) solamente surge cuando esa plenitud no es alcanzada y objetos parciales dentro de la sociedad (objetivos, figuras, símbolos) son investidos de tal manera que se convierten en los nombres de su ausencia. Pienso que queda claro a partir de nuestra discusión por qué la dimensión afectiva es decisiva en este proceso". (Laclau, 2005, p. 149).

22 "De una manera paradójica, definir un conjunto de enunciados en lo que hay en él de individual consistiría en describir la dispersión de esos objetos, captar todos los intersticios que los separan, medir las distancias que reinan entre ellos; en otros términos: formular su Iey de repartición (...). No se buscaría ya entonces una arquitectura de conceptos lo bastante generales y abstractos para significar todos los demás e introducirlos en el mismo edificio deductivo: se probaría a analizar el juego de sus apariciones y de su dispersión”. (Foucault, 2008, pp. 55-57)

23 “(...) ¿qué forma la representación del vacío? Hemos sostenido que la totalización del campo popular -la cristalización discursiva del momento plenitud/vacío -solo puede tener lugar si un contenido parcial adopta la representación de una universalidad que es inconmensurable con él" (Laclau, 2005, p. 137).

24 Laclau define el significante vacío y su importancia en la cadena de demandas y su traducción o equivalencia en los siguientes términos: "Cada una de estas demandas en su particularidad es diferente de todas las otras (...). Sin embargo, todas ellas son equivalentes entre sí en su oposición común al régimen opresivo (...). Esto, como hemos visto, conduce a que una de las demandas intervenga y se convierta en el significante de toda la cadena de un significante trascendentalmente vacío (...)" (Laclau, 2005, p. 165). Como vemos, por el ejemplo citado en el cuerpo del texto, el significante vacío no solamente se puede imaginar como el nombre de una demandada 


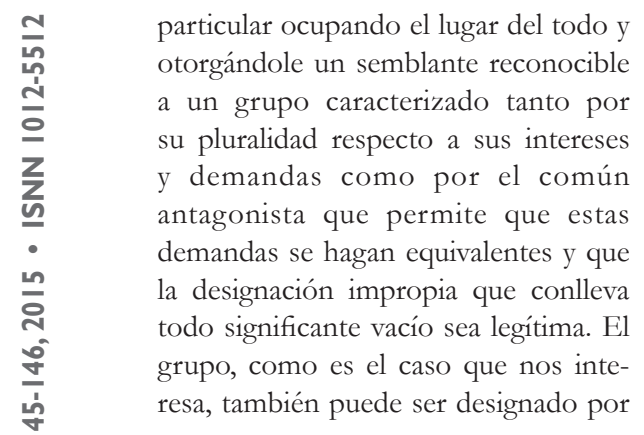

un nombre que se limita a señalar la universal carencia (pobres son aquellos que carecen, debido a una usurpación ilegítima por un agente de poder, de un atributo fundamental que limita su rol de actores sociales y públicos) de los diversos sujetos que lo constituyen. En ese sentido, por ser el nombre de una carencia universal, el significante "pobre" también puede ser considerado vacío. 